\title{
Article
}

Arq Neuropsiquiatr 2011;69(6):938-942

\section{Behavioral investigation of mice with experimental autoimmune encephalomyelitis}

\author{
David Henrique Rodrigues, Márcia de Carvalho Vilela, \\ Norinne Lacerda-Queiroz, Aline Silva de Miranda, \\ Larissa Fonseca da Cunha Sousa, Helton José dos Reis, \\ Antônio Lúcio Teixeira
}

\begin{abstract}
Multiple sclerosis is a neuroinflammatory disease that results in serious neurological disability. Besides physical impairment, behavioral symptoms are also common in patients with multiple sclerosis. Experimental autoimmune encephalomyelitis (EAE) is considered to be a model of multiple sclerosis and mimics the main features of the disease, such as demyelination and motor impairment. In this work, we aimed to study behavioral parameters in animals with EAE using the $\mathrm{MOG}_{35-55}$ model in C57BL/6 mice. We analyzed memory and anxiety in animals using the elevated plus maze, the step down inhibitory avoidance task and the memory recognition test. No differences in any tests were found when comparing controls and animals induced with EAE. Therefore, we conclude that behavioral changes in animals with EAE induced with $\mathrm{MOG}_{35-55}$ are probably subtle or absent. Key words: multiple sclerosis, experimental autoimune encephalomyelitis, behavior, memory, anxiety.
\end{abstract}

Investigação comportamental de camundongos com encefalomielite autoimune experimental

\section{RESUMO}

Esclerose múltipla é uma doença neuroinflamatória que resulta em séria incapacidade neurológica. Além do comprometimento físico, sintomas comportamentais também são comuns em pacientes com esclerose múltipla. A encefalomielite autoimune experimental (EAE) é considerada um modelo de esclerose múltipla e mimetiza as principais características da doença, como a desmielinização e a fraqueza motora. Neste trabalho, objetivamos estudar parâmetros comportamentais em animais com EAE usando o

\section{Correspondence}

David Henrique Rodrigues Laboratório de Imunofarmacologia Instituto de Ciências Biológicas Universidade Federal de Minas Gerais Av. Antônio Carlos 6627 31270-901 Belo Horizonte MG - Brasil E-mail: dhenrodrigues@gmail.com

\section{Conflicts of interest}

The authors report no

conflicts of interest

\section{Support}

Financial support: CAPES,

CNPq, FAPEMIG

Received 3 May 2011

Received in final form 11 July 2011

Accepted 18 July 2011

modelo de $\mathrm{MOG}_{35-55}$ em camundongos $\mathrm{C57BL/6}$. Analisamos memória e ansiedade em animais utilizando o labirinto em cruz elevado, o teste da esquiva inibitória e o teste de memória de reconhecimento. Nenhuma diferença em quaisquer dos testes foi encontrada comparando animais controles e animais induzidos com EAE. Assim, concluímos que alterações comportamentais em animais com EAE induzidos com $\mathrm{MOG}_{35-55}$ são provavelmente sutis ou ausentes.

Palavras-Chave: esclerose múltipla, encefalomielite autoimune experimental, comportamento, memória, ansiedade.

Multiple sclerosis (MS) is considered an autoimmune inflammatory disease and is one of the main causes of motor dis- ability in young adults. Its defining pathological feature is the presence of central nervous system (CNS) demyelinating le- 
sions in association with inflammatory infiltrates. Even though the main symptoms of MS are related to motor and sensory dysfunction, behavioral and cognitive changes have also been frequently reported. Among behavioral disorders, depression is the most frequent, affecting approximately $30 \%$ of MS patients ${ }^{1}$. Many cognitive domains are impaired in MS, including attention, visuospatial abilities, memory, information processing speed and executive function ${ }^{2,3}$.

To better understand the etiopathogenesis of MS, researchers use some experimental models and, among these, one of the most used is the experimental autoimmune encephalomyelitis (EAE). Despite being traditionally related to motor dysfunction, in recent years some papers have reported behavioral changes in EAE. Pollak and collaborators ${ }^{4}$ named the expression EAE behavioral syndrome to refer to the behavioral changes that occur in SJL/J mice with EAE induced with proteolipid protein peptide $\left(\mathrm{PLP}_{139-151}\right)$. Pollak and collaborators found that EAE animals presented low social interaction and low sucrose consumption when compared to controls ${ }^{5}$.

Only a few works have studied behavioral changes after the reports of Pollak. In the present work, we sought to investigate behavioral changes in a model of EAE induced with $\mathrm{MOG}_{35-55}$ in C57BL/6 mice.

\section{METHOD}

\section{Mice}

Seventy nine female C57BL/6 mice were obtained from Animal Care Facilities of the Institute of Biological Sciences, Universidade Federal de Minas Gerais (UFMG, Brazil), aged between nine and ten weeks. The Animal Ethics Committee of UFMG approved all experimental procedures used (protocol number: 129/2006).

\section{EAE induction and clinical assessment}

EAE was induced using an emulsion containing myelin oligodendrocyte glycoprotein (MOG), Complete Freund's Adjuvant (CFA) and attenuated Mycobacterium tuberculosis. Pertussis toxin was injected separately and intraperitoneally. MOG peptide, sequence 35-55 (MEVGWYRSPFSRVVHLYRNGK; Auspep) was obtained from NeoMPS (San Diego, USA). Pertussis toxin and CFA were purchased from Sigma Chemical Co (St. Louis, MO, USA). Attenuated M. tuberculosis H37 RA was purchased from Difco Laboratories (Sparks, MD, USA). Each animal received $100 \mu \mathrm{L}$ of the emulsion in the base of tail containing $100 \mu \mathrm{g}$ of $\mathrm{MOG}_{35-55}$. Each animal received two i.p. doses of $300 \mathrm{ng}$ of pertussis toxin in the day of the immunization and 48 hours later.

Animals were monitored daily and clinical score was evaluated using a standardized scoring system ${ }^{6}$. Briefly, clinical signs were scored as follows: $0=$ no signs;
$0.5=$ tail weakness; $1=$ tail paralysis; $2=$ hind limb weakness; $3=$ hind limb paralysis; $4=$ hind limb paralysis and front limb weakness. Animals were also weighed daily.

\section{The elevated plus maze (EPM)}

Anxiety-like behavior was evaluated on days nine and 60 after EAE induction. The elevated plus maze (EPM) is a test of unconditioned anxiety-related behavior that involves a conflict between the rodent's desire to explore a novel environment and anxiogenic elements such as elevation and an unfamiliar open area ${ }^{7}$. This is a widely used test for anxiety behavior of rodents ${ }^{7-9}$. The EPM test was conducted as previously described ${ }^{10}$. Briefly, mice were placed in the center of the maze facing an open arm and were allowed to freely explore the EPM for five minutes. The animal placing all four paws onto the arm was considered to be in the arm, otherwise the animal was in the center of the maze. Behavior that was recorded when rodents were in the EPM included the time spent and entries made on the open and closed arms. The measures of anxiety were the percentage (\%) of open arm entries and the percentage (\%) of time spent on the open arms. The number of closed arm entries was considered as a locomotor activity measure. Decreased open arm activities indicate increased anxiety levels in EPM. Between each trial, the maze was wiped clean with a damp sponge and dried with paper towels. Before behavioral assessment, animals were allowed to accommodate to their new environment for two days.

\section{Inhibitory avoidance task}

The inhibitory avoidance step down test was used as described previously ${ }^{11}$. Briefly the apparatus was a $50 \times 25 \times 25 \mathrm{~cm}$ acrylic box, whose floor consisted of parallel stainless-steel bars ( $1 \mathrm{~mm}$ diam.) spaced $1 \mathrm{~cm}$ apart. A $7 \mathrm{~cm}$ wide $\times 2.5 \mathrm{~cm}$ high platform was placed on the floor of the box against the left wall. Animals were placed on the platform and their latency to step down on the grid with all four paws was measured with an automatic device. In training sessions, immediately after stepping down on the grid, the animals received a 2.0 seconds scrambled foot shock. The shock intensity was $0.4 \mathrm{~mA}$ for animals given one training session. In test sessions performed 1 hour and 30 minutes and 24 hours after training session, no foot shock was administered and the step-down latency (maximum 180 seconds) was used as a measure of retention.

\section{Object recognition task}

The object recognition test was done as described elsewhere ${ }^{12}$. This task is based on the spontaneous preference of rodents for novelty and their ability to remember previously encountered objects ${ }^{13,14}$. The task assesses the ability of mice to discriminate between a novel 
and a familiar object ${ }^{15}$. Briefly, testing entailed placing mice in an arena $(40 \mathrm{~cm}$ long, $20 \mathrm{~cm}$ high and $40 \mathrm{~cm}$ wide) with two objects, with a familiarization session in the previous day. In the exploration day, the two objects are identical and mice are placed in the arena for five minutes. The time the animal spent exploring each object was recorded. Recognition memory was tested 1.5 hour and one day after the exploration phase. Mice were reintroduced into the arena and exposed to two objects, a familiar object and a novel object, whose positions were identical to the exploration session. The arena and the objects used were cleaned thoroughly between each mouse to ensure the absence of olfactory cues.

\section{Statistical analysis}

The Kolmogorov-Smirnov test was used to verify normality of samples. In samples with Gaussian distribution, we used parametric t-test. In samples without Gaussian distribution, we used non-parametric Mann-Whitney test. Statistical significance was defined as $\mathrm{p}<0.05$.

\section{RESULTS}

\section{Development of EAE}

EAE was induced and animals presented clinical signs beginning at day 11 after induction, with a peak of clinical signs after 17 days. Partial improvement of motor disabilities occurred between days 17 and 25. After 25 days, motor status did not change. Behavioral tests were performed in days nine and 60 after induction.

\section{No change in anxiety level in mice with EAE}

After nine days of EAE induction, one day before motor signs development, animals were evaluated in the EPM (Fig 1). No animals presented motor disability at this day. No differences in open arm exploration were detected ( $\mathrm{p}=0.15$ ) between controls (percentage of total exploration, mean \pm SE: $18.67 \pm 5.04$ ) and mice with EAE (10.31 \pm 3.13$)$. After 60 days of EAE induction, animals were evaluated again. At this day, as some EAE mice still presented motor impairment, only animals with a score of up to one (tail weakness) were studied. No differences were detected $(\mathrm{p}=0.20)$ between controls $(22.59 \pm 7.21)$ and animals with EAE $(41.38 \pm 12.08)$.

\section{No change in memory in mice with EAE}

The step-down inhibitory test was used at nine days of induction, while the object recognition test was used after 60 days of induction to test memory. In the step down inhibitory test (Fig 2), no changes were found in the latency of step down 1h30min (median [range]; con-
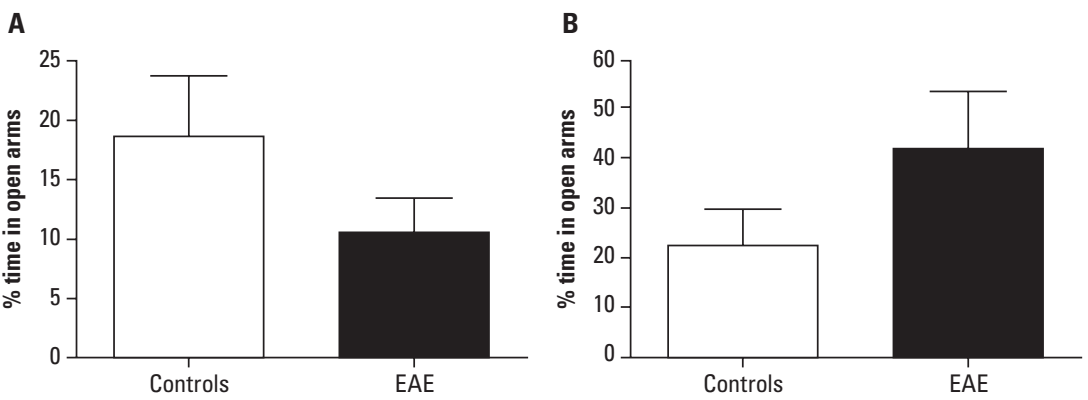

Fig 1. Percentage of time spent in open arms in the elevated plus maze. Animals with $E A E$ after nine $(A, n=15)$ and 60 days of induction $(B, n=8)$ were tested. No differences were found between EAE induced animals and controls $(n=10)$. EAE: experimental autoimmune encephalomyelitis.

A

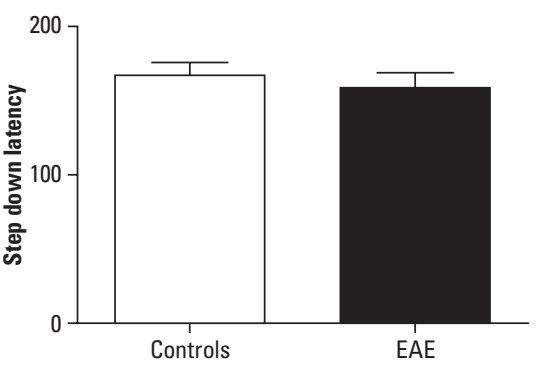

B

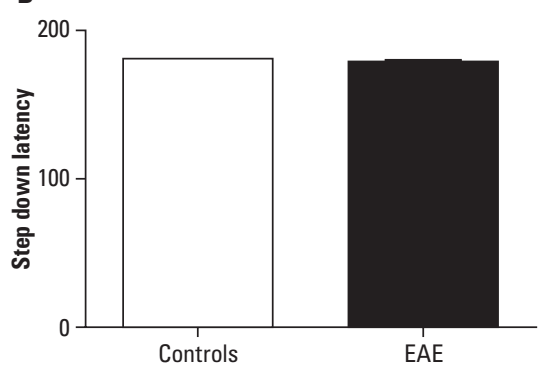

Fig 2. Step down latency in the Step Down Inhibitory Avoidance task. At 9 days of induction, animals with EAE $(n=15)$ had similar step down latency when compared to non-induced EAE mice ( $n=15) 1 \mathrm{~h} 30 \mathrm{~min}[A]$ and $24 \mathrm{~h}[B]$ after receiving aversive stimulus. EAE: experimental autoimmune encephalomyelitis. 
A

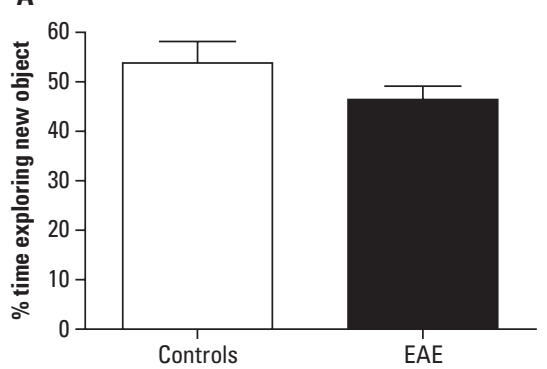

B

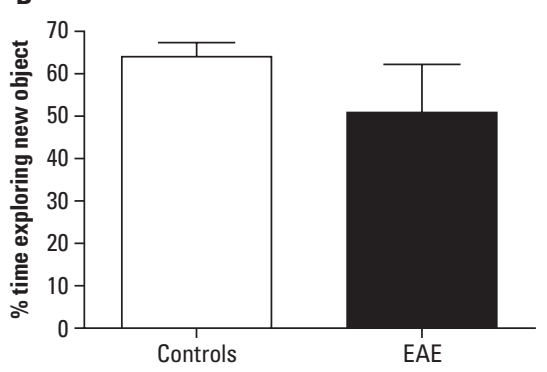

Fig 3. Percentage of time exploring new object in the object recognition test. At 60 days of induction, animals with EAE $(n=8)$ presented similar exploration of the new object when compared to controls $(n=8)$. Animals were evaluated for short term $[A]$ and long term $[B]$ memory. EAE: experimental autoimmune encephalomyelitis.

trols: 180.0 [77.0-180]; EAE: 180.0 [25.0-180.0]) and 24h (controls: 180.0 [178.0-180.0]; EAE: 180.0 [150.0-180.0]) after the training session (Fig $2 \mathrm{~A}$ and $2 \mathrm{~B}$ ).

After 60 days of EAE induction, no significant changes were found in the exploration of the new objects by animals induced with EAE either $1 \mathrm{~h} 30 \mathrm{~min}$ (in seconds; mean \pm SE; $53.80 \pm 4.30)$ or $24 \mathrm{~h}(45.90 \pm 3.30)$ after the exposure to the first object ( $\mathrm{p}=0.17$ ), as it can be seen in Figure 3.

\section{DISCUSSION}

In the present work, we did not find clear behavioral changes in mice with EAE, either in the acute phase or after the remission of clinical signs.

The EAE model has some differences when compared to multiple sclerosis. In spite of the similar motor dysfunction, which involves weakness of limbs, in EAE, the $\mathrm{CNS}$ area affected is primarily the spinal cord. However, in recent years, some studies have detected evidence of inflammation and neuronal changes in the brain of mice with $\mathrm{EAE}^{16,17}$. In previous works from our group, we have also found increased number of cells rolling and adhering in meningeal vessels and inflammatory infiltrate in the brain from EAE mice ${ }^{6,18}$.

As a result of brain dysfunction, it could be expected that animals with EAE might present behavioral disturbances. Indeed, Pollak and collaborators ${ }^{5}$ reported sickness behavior in EAE, including symptoms of anorexia, reduced social exploration, and decreased preference for sucrose solution. It is worth mentioning that Pollak used an EAE model induced with proteolipid protein in SJL/J mice. Conversely, Levy and collaborators ${ }^{19}$, studying an EAE model similar to the current work, found no evidence of brain lesions in C57BL/6 mice. Furthermore, Brown and Sawchenko ${ }^{16}$ using C57BL/6 mice and the $\mathrm{MOG}_{35-55}$ model found only minor $\mathrm{T}$ cell infiltration in CNS without neuronal degeneration before 10 days of induction and the areas compromised were the choroid plexus, the meninges (both in the brain and in the spinal cord), olfactory bulbs and the circumventricular organs. MacKenzie-Graham and collaborators ${ }^{20}$ also found evidence of non-spinal lesions with important cerebellar gray matter cell death, especially Purkinje cells. However, none of the previous works found consistent evidence of brain inflammation and neurodegeneration before the onset of motor symptoms. It is possible that brain inflammation is associated with behavioral changes only at the peak of the acute phase of EAE when motor signs are at maximum severity.

The possibility of behavioral changes coinciding with the most severe phase of EAE raises an important question. How is it possible to measure the supposed behavioral changes considering that all behavioral tests depend on motor function? For example, Jones and collaborators ${ }^{21}$ found differences in the open field test in the number of crossings of animals with EAE compared to controls. However, it is not possible to conclude whether this outcome is a result of motor impairment or it is a behavioral change. Peruga and collaborators ${ }^{22}$ solved this problem by using a model of mild EAE based on the reduction of the amount of pertussis toxin. While this is a good strategy to significantly attenuate the motor impairment, the mechanism that leads to the behavioral changes may be completely different.

It is also relevant to state that the low sensitivity of the elevated plus maze test may be responsible for the lack of detection of subtle changes in anxiety. Peruga and collaborators ${ }^{22}$ used the dark-light box to evaluate anxiety in animals with mild EAE, and they found an increase of anxiety in these animals. Therefore, the elevated plus maze may not be a sensitive model to study anxiety in EAE.

We also evaluated short term and long term episodic memory with the object recognition test and short term and long term aversive memory using the inhibitory avoidance task. Hippocampal lesions were reported in 
the brain of multiple sclerosis patients $\mathrm{s}^{23,24}$ and also in animals with $\mathrm{EAE}^{17,25}$. However, the presence of lesions in hippocampus is still a matter of debate since Brown and Sawchenko ${ }^{16}$ concluded that the hippocampus does not show neurodegeneration concurrent with T-cell infiltration and/or microglial activation. Thus, the lack of inflammation or neurodegeneration of limbic structures, as the hippocampus, may be the reason for the absence of memory impairment in our work. These results are in contradiction with data obtained by Ziehn and collaborators ${ }^{17}$ who found decreased volume of CA1, loss of inhibitory interneurons and increase in death of hippocampal glia and neurons. Even though both Ziehn and Brown used C57BL/6 mice and the MOG $35-55$ to induce EAE, Ziehn used male mice, whereas Brown and Sawchenko used female mice. It is possible that lesions occur only during the most severe phase of EAE in female mice and, after remission, the area recovers. Another possibility is that, by unknown reasons, the neuronal lesions in female mice are less severe than those present in male mice. Further studies are needed to address this point.

In this study, we could not detect significant behavioral symptoms in the EAE model. The inflammatory changes occurring in the brain were not sufficient to alter the behavior of EAE animals.

\section{REFERENCES}

1. Chwastiak L, Ehde DM, Gibbons LE, Sullivan M, Bowen JD, Kraft GH Depressive symptoms and severity of illness in multiple sclerosis: epidemiologic study of a large community sample. Am J Psychiatry 2002;159: 1862-1868.

2. Engel C, Greim B, Zettl UK. Diagnostics of cognitive dysfunctions in multiple sclerosis. J Neurol 2007;254(Suppl 2):S30-S34

3. Ferreira ML. Cognitive deficits in multiple sclerosis: a systematic review. Arq Neuropsiquiatr 2010;68:632-641.

4. Pollak Y, Orion E, Goshen I, Ovadia H, Yirmiya R. Experimental autoimmune encephalomyelitis-associated behavioral syndrome as a model of 'depression due to multiple sclerosis'. Brain Behav Immun 2002;16:533-543.

5. Pollak Y, Ovadia H, Goshen I, et al. Behavioral aspects of experimental autoimmune encephalomyelitis. J Neuroimmunol 2000;104:31-36.

6. Rodrigues DH, Vilela MC, Barcelos LS, Pinho V, Teixeira MM, Teixeira AL. Absence of PI3Kgamma leads to increased leukocyte apoptosis and diminished severity of experimental autoimmune encephalomyelitis. J Neuroimmunol 2010;222:90-94.
7. Lister RG. The use of a plus-maze to measure anxiety in the mouse. Psychopharmacology 1987;92:180-185.

8. File SE. Factors controlling measures of anxiety and responses to novelty in the mouse. Behav Brain Res 2001;125:151-157.

9. Miranda AS, Lacerda-Queiroz N, Vilela MC, et al. Anxiety-like behavior and proinflammatory cytokine levels in the brain of C57BL/6 mice infected with Plasmodium berghei (strain ANKA). Neurosci Lett 2011;491:202-206.

10. Walf AA, Frye CA. The use of the elevated plus maze as an assay of anxietyrelated behavior in rodents. Nat Protoc 2007;2:322-328.

11. Quevedo J, Vianna MR, Roesler R, de-Paris F, Izquierdo I, Rose SP. Two time windows of anisomycin-induced amnesia for inhibitory avoidance training in rats: protection from amnesia by pretraining but not pre-exposure to the task apparatus. Learn Mem 1999;6:600-607.

12. Goodman T, Trouche S, Massou I, et al. Young hippocampal neurons are critical for recent and remote spatial memory in adult mice. Neuroscience 2010;171:769-778.

13. Ennaceur A, Delacour J. A new one-trial test for neurobiological studies of memory in rats. 1: Behavioral data. Behav Brain Res 1988;31:47-59.

14. Dodart JC, Mathis C, Ungerer A. Scopolamine-induced deficits in a twotrial object recognition task in mice. Neuroreport 1997;8:1173-1178.

15. Winters BD, Forwood SE, Cowell RA, Saksida LM, Bussey TJ. Double dissociation between the effects of peri-postrhinal cortex and hippocampal lesions on tests of object recognition and spatial memory: heterogeneity of function within the temporal lobe. J Neurosci 2004;24:5901-5908.

16. Brown DA, Sawchenko PE. Time course and distribution of inflammatory and neurodegenerative events suggest structural bases for the pathogenesis of experimental autoimmune encephalomyelitis. J Comp Neurol 2007;502:236-260.

17. Ziehn MO, Avedisian AA, Tiwari-Woodruff S, Voskuhl RR. Hippocampal CA1 atrophy and synaptic loss during experimental autoimmune encephalomyelitis, EAE. Lab Invest 2010;90:774-786.

18. Rodrigues DH, Lacerda-Queiroz N, Miranda AS, et al. Absence of PAF receptor alters cellular infiltrate but not rolling and adhesion of leukocytes in experimental autoimmune encephalomyelitis. Brain Res 2011;1385: 298-306.

19. Levy $H$, Assaf $Y$, Frenkel D. Characterization of brain lesions in a mouse model of progressive multiple sclerosis. Exp Neurol 2010;226:148-158.

20. MacKenzie-Graham A, Tiwari-Woodruff SK, Sharma G, et al. Purkinje cell loss in experimental autoimmune encephalomyelitis. Neuroimage 2009; 48:637-651.

21. Jones MV, Nguyen TT, Deboy CA, et al. Behavioral and pathological outcomes in MOG 35-55 experimental autoimmune encephalomyelitis. J Neuroimmunol 2008;199:83-93.

22. Peruga I, Hartwig S, Thöne J, et al. Inflammation modulates anxiety in an animal model of multiple sclerosis. Behav Brain Res 2011;220:20-29.

23. Calabrese M, Rocca MA, Atzori M, et al. A 3-year magnetic resonance imaging study of cortical lesions in relapse-onset multiple sclerosis. Ann Neurol 2010;67:376-383.

24. Sicotte NL, Kern KC, Giesser BS, et al. Regional hippocampal atrophy in multiple sclerosis. Brain 2008;131:1134-1141.

25. Pomeroy IM, Jordan EK, Frank JA, Matthews PM, Esiri MM. Focal and diffuse cortical degenerative changes in a marmoset model of multiple sclerosis. Mult Scler 2010;16:537-548. 